\title{
Buried lumen-apposing metal stent (LAMS) in esophagogastric anastomosis: the LAMS-in-LAMS rescue treatment
}

A 61-year-old man presented with progressive dysphagia and post-prandial vomiting 1 year after undergoing an esophagogastric anastomosis for adenocarcinoma of the gastroesophageal junction. Upper gastrointestinal endoscopy revealed a high grade, anastomotic stricture (1 cm in length) at $25 \mathrm{~cm}$ from the incisors, which failed to respond to multi-

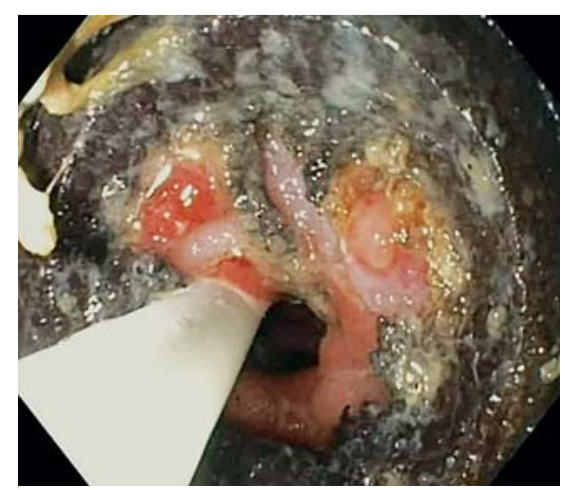

> Fig. 1 Endoscopic view showing a buried lumen-apposing metal stent at the esophagogastric anastomosis with only part of its proximal flange visible. ple, serial $15-\mathrm{mm}$ balloon dilation sessions. He subsequently underwent uneventful placement of a lumen-apposing metal stent (LAMS; Axios, 15-mm diameter; Boston Scientific, Marlborough, Massachusetts, USA). This resulted in complete resolution of his symptoms.

A follow-up endoscopy was performed at 6 months, during which it was found that almost the entire LAMS was embedded with significant tissue overgrowth ( Fig.1). A second 15-mm LAMS was placed using the "stent-in-stent" technique, completely overlapping the first LAMS ( $>$ Fig. 2). At a further follow-up endoscopy 3 months later, both LAMSs were easily removed in an atraumatic fashion using rat-tooth forceps ( $\triangleright$ Video 1 ). Inspection of the first LAMS after its removal revealed complete disintegration of its coating, which had led to its embedding, because of the prolonged in-dwell time (> Fig. 3).

Tissue overgrowth resulting in embedding of LAMSs is a rare complication [1]. It results from the foreign body reaction when the stents are used for the man- agement of benign strictures. In the setting of benign tissue hyperplasia, forcible removal of the stent has been reported to cause luminal perforation $[2,3]$. Therefore, the stent-in-stent technique has gained greatest acceptance among endoscopists for removal of embedded covered metal stents $[2,4]$. This technique involves placement of another stent, which entirely covers the inside of the trapped stent. This second stent should be of the same diameter in order to achieve tissue necrosis of the hyperplasia, which subsequently results in easy atraumatic removal of the embedded stent.

To our knowledge, this is the first report of the successful removal of an embedded LAMS using the stent-in-stent technique.

Endoscopy_UCTN_Code_CPL_1AL_2AD

Competing interests

None
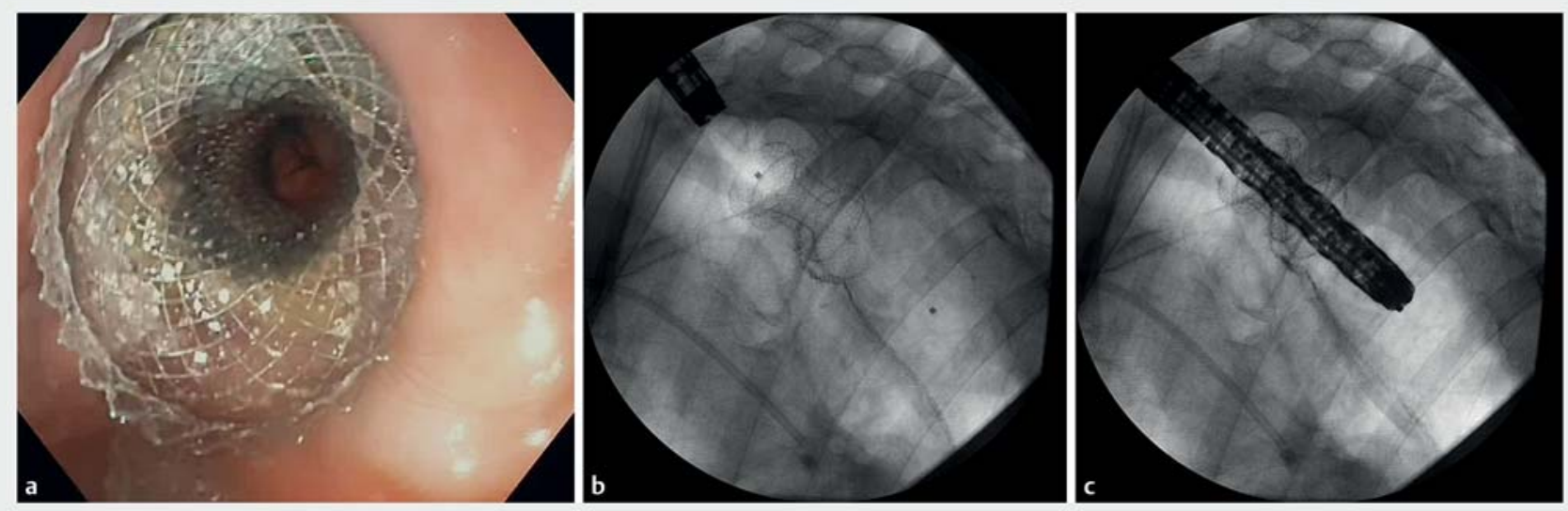

- Fig. 2 Placement of the second lumen-apposing metal stent (LAMS), seen on: a endoscopic view; b fluoroscopic view showing the second LAMS being placed using the stent-in-stent technique; c fluoroscopic view showing passage of an endoscope through the stricture after the second LAMS had been placed. 


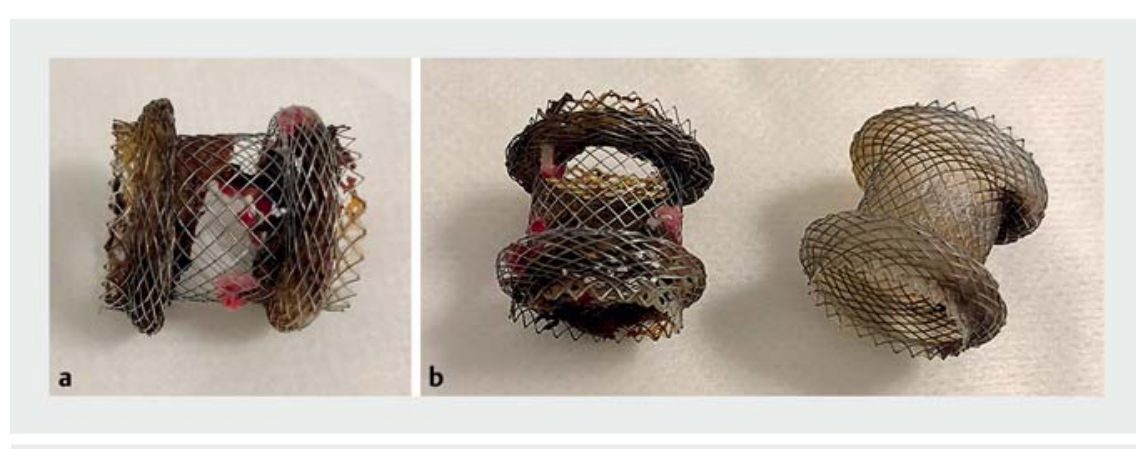

Fig. 3 Images of the removed lumen-apposing metal stents (LAMSs) showing: a the first LAMS with complete disintegration of the coating; $\mathbf{b}$ both LAMSs side by side.
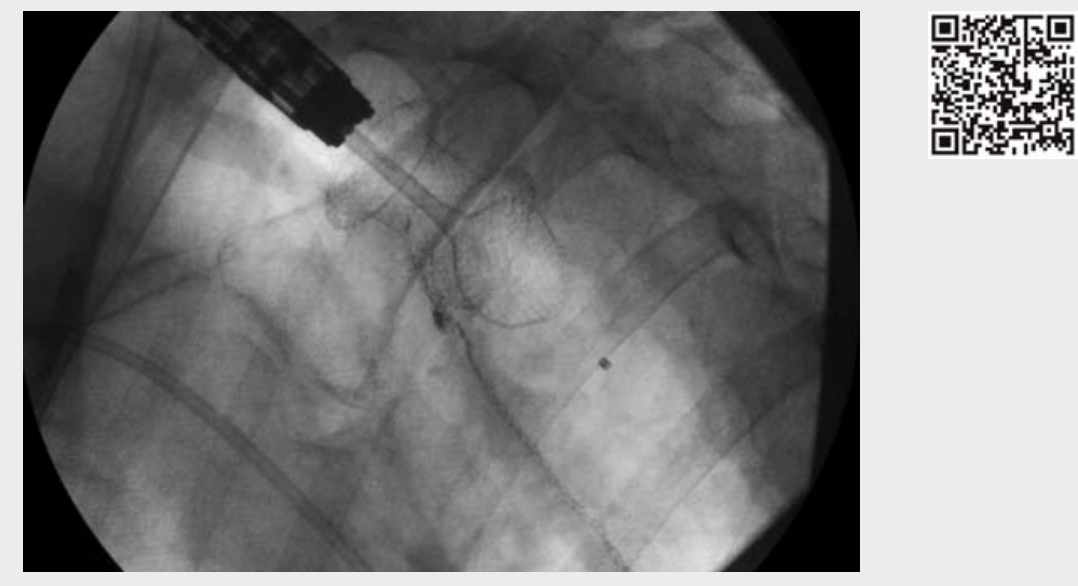

Video 1 Video showing placement of the first lumen-apposing metal stent (LAMS) across an esophagogastric stricture. After 6 months, almost the entire LAMS is found to be embedded, with significant tissue overgrowth and a second 15-mm LAMS is placed using the stent-in-stent technique. Finally, 1 month later, both LAMSs are easily removed.
The authors

Sergio Bazaga Pérez de Rozas ${ }^{1}$, Prabhleen Chahal $^{2}$, Ramon Sánchez-Ocaña ${ }^{1}$, Francisco Javier García-Alonso', Ana Yaiza Carbajo', Carlos de la Serna-Higuera ${ }^{1}$, Pérez-Miranda Manuel ${ }^{1}$

1 Gastroenterology and Endoscopy Department, Hospital Universitario Rio Hortega, Valladolid, Spain

2 Gastroenterology and Hepatology Department, Digestive Disease Institute, Cleveland Clinic Foundation, Cleveland, Ohio, USA
[1] Bang JY, Navaneethan U, Hasan MK et al. Non-superiority of lumen-apposing metal stents over plastic stents for drainage of walled-off necrosis in a randomised trial. Gut 2018. doi:10.1136/gutjnl-2017-315335

[2] Ligresti D, Cipolletta F, Amata M et al. Buried lumen-apposing metal stent (LAMS) following endoscopic ultrasound-guided gallbladder drainage: The LAMS-in-LAMS rescue treatment. Endoscopy 2018; 50: 822-823

[3] Irani S, Kozarek RA. The buried lumen-apposing metal stent: Is this a stent problem, a location problem, or both? Gastrointest Endosc 2016; 1: 25-26

[4] Abdel-aziz Y, Renno A, Hammad T et al. Rare esophageal migration of AXIOS stent used for walled-off pancreatic necrosis drainage. ACG Case Rep J 2017; 4: 73 - 75

\section{Bibliography}

DOI https://doi.org/10.1055/a-0861-9907

Published online: 13.3.2019

Endoscopy 2019; 51: 600-601

(c) Georg Thieme Verlag KG

Stuttgart · New York

ISSN 0013-726X

\section{ENDOSCOPY E-VIDEOS}

https://eref.thieme.de/e-videos

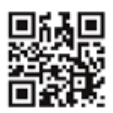

Endoscopy E-Videos is a free access online section, reporting on interesting cases and new techniques in gastroenterological endoscopy. All papers include a high quality video and all contributions are freely accessible online.

This section has its own submission website at https://mc.manuscriptcentral.com/e-videos
Bazaga Sergio Pérez de Rozas, MD Hospital Universitario Río Hortega Gastroenterology, Calle Dulzaina, 2 Valladolid, Valladolid 47012, Spain sergio.bpr@gmail.com 